\section{Problems of Land Reform in Under-developed Countries}

IN the under-developed regions of the world there are many impediments to the improvement of rural living standards. Among them are the fragmentation of holdings, the concentration of land ownership in a few hands, high rents and insecurity of tenure, low wages, exorbitant taxation and inadequate provision for agricultural credit. In a report, entitled "Land Reform: Defects in Agrarian Structure as Obstacles to Economic Development", published by the United Nations' Department of Economic Affairs (pp. 101. New York: United Nations. 75 cents. London: H.M.S.O., 1951. 5s.), it is emphasized that it is the agrarian structure and, in particular, systems of land tenure which prevent a rise in the standard of living of small farmers and agricultural labourers. Land reform, however, if it is to be effective, must comprise improvement in all the social and economic conditions affecting farm life. Changes in the land tenure systems are more likely to lead to a rise in the standard of living of the rural community when they form part of a general programme than when they are undertaken in isolation. The provision of credit facilities, co-operative marketing, technical advice and health services are among the major services needed. The report points out that if steps are not taken to provide facilities of these kinds to newly established small farmers, many of the benefits which might be expected to result from reform of the land tenure system will be nullified.

\section{Eradication of Bovine Tuberculosis from Cattle in Denmark}

DENMARK, with some $1,600,000$ dairy cows, has recently completed the eradication of bovine tuberculosis from among her herds, and is the first country in the world to guarantee that all exports of butter and cheese are from the milk of tubercle-free animals only. The occasion was marked by official celebrations in Copenhagen on June 13. The campaign was begun sixty years ago, when Prof. Bernhard Bang, of the Royal Veterinary College, Copenhagen, advocated the tuberculin-testing of all cattle, the isolation of the-healthy animals, and the weeding out of reactors ; its completion involved the slaughter of 318,000 reactors between 1934 and 1951 ("The Campaign against Bovine Tuberculosis in Denmark and its Eradication." By T. Mathiassen. Aarhus : by the Danish Federation of Dairy Associations. 'Re Lur' branded butter and cheese: Order of Danish Ministry of Agriculture, March 27, 1952).

\section{Ethics of Management}

A STRIKING article in the current issue of the Journal of the Institute of Personnel Management (34, No. 319) is one by the Institute's director, Mr. H. E. Roff, on the ethics of management. Accepting the four-fold aim of industry as the provision of goods and services, the earning of profit on capital, the provision of employment and the provision of social and work satisfaction, Roff suggests that management has responsibility to the customer, the shareholder, the employee and the community, the latter including responsibility for preserving the amenities of Britain, making effective use of natural resources, helping to produce democratic citizens and, finally, toaching the new generation of managers. The journal also contains an account of the workshop for elderly men at Rubery Owen and Co., an examination of the scientific study of human relations in industry, the report of a morale survey in a Danish department store, and the part played by trade unions in German industry. There are also some interesting notes on the training of shop stewards and the employment of older workers as well as the usual reviews of books and periodicals.

Imperial College of Science and Technology, London: Report for the Year 1950-51

THE forty-fourth annual report of the Governing Body of the Imperial College of Science and Technology, London (pp. 55 ; from the College at South Kensington, London, S.W.7 ; 1951), covering the year ended July 31, 1951, refers to the further special grants of $£ 3,000$ made by the University Grants Committee in 1950-51 rising in 1951-52 to $£ 4,000$ for the provision of bursaries for postgraduate students in engineering. The first of the projected extensions to the chemical technology building and the new chemistry laboratories were completed during the year, adaptation of the Union building was nearing completion and the erection of laboratories for mineral dressing by adaptation of part of the Bessemer Laboratory is expected to be complete in August 1952. In spite of continuous progress in developments on the technological side, increasing costs have checked the steady advance in the quality and quantity of the work of the College during the first four years of the quinquennium. A deficit of more than $£ 9,000$ was incurred in 1949-50, and much larger deficits are anticipated in 1950-52. The finances have accordingly been closely examined to determine the directions in which economies are possible with the minimum reduction of efficiency. Capital grants from the University of London for new construction and equipment totalled $£ 154,290$; but room for expansion constitutes a serious problem. The plan for a South Kensington site has come no nearer to fruition; but the acquisition of the sites at 181-5 Queen's Gate and of the underlease of the property at 177 Queen's Gate should provide sufficient room for necessary normal development in the next five or ten years. Appendixes to the report include, besides the statement of accounts, a list of publications during $1950-51$, arranged by departments.

\section{Interpretation of Seismograms}

PrIOR to the year 1930 seismologists were obliged to acquire information required for the interpretation of seismograms piecemeal from papers and portions of books on seismology, and from a careful study of their own particular instruments. In 1930 they became indebted to Dr. Frank Neumann, mathematician of the United States Coast and Geodetic Survey, for collecting these data and for making them available in mimeographed form. With the advance of the science of seismology it has now been necessary for Dr. Neumann to revise and enlarge his original work on this subject, and seismologists are now indebted to the Coast and Geodetic Survey for printing the work as Special Publication No. 254, "Principles Underlying the Interpretation of Seismograms". This work, which has been brought thoroughly up to date, is written for the Seismograph Station director, for the student who is beginning his career as a seismologist, or for the amateur seismologist. The reader is provided with basic background information pertaining to the origin and transmission of seismic waves and the recording characteristics of the principal types of seismographs now used in 